\title{
A NEW CATEGORY OF COMMON PURPOSE LIABILITY?
}

\section{$1 \quad$ Introductory remarks}

Common purpose liability remains a controversial aspect of the principles of criminal liability in South African law, despite the doctrine passing constitutional muster in $S v$ Thebus (2003 (2) SACR 319 (CC)). In the case of Thebus (par 18), the Constitutional Court approved Burchell's definition of this doctrine, which states the following:

"Where two or more people agree to commit a crime or actively associate in a joint unlawful enterprise, each will be responsible for the specific criminal conduct committed by one of their number which falls within their common design."

This definition was most recently set out in the latest edition of Burchell's Principles of Criminal Law (5ed (2016) 477). It is clear from the definition that the common purpose doctrine can apply in two scenarios: first, where there is a prior agreement between persons to commit a crime, and secondly, where there is an intentional active association with the commission of the crime (this is generally accepted in the case law: see $S$ v Mgedezi 1989 (1) SA 687 (A) 705-6; S v Mitchell 1992 (1) SACR 17 (A) 21-23; S v Thebus supra par 19; S v Mzwempi 2011 (2) SACR 237 (ECM) par 76 and 124). Where either of these situations can be established on the facts of the case, it is not necessary for the State to prove a causal contribution on the part of all of those involved in the criminal conduct, since the conduct of the individual who caused the consequence is imputed to all the others who are involved. The requirements for liability in terms of the form of common purpose which occurs through active association were authoritatively set out, in the context of the crime of murder, in $S v$ Mgedezi (supra 705I-706B):

"In the first place, he must have been present at the scene where the violence was being committed. Secondly, he must have been aware of the assault on the inmates of room 12. Thirdly, he must have intended to make common cause with those who were actually perpetrating the assault. Fourthly, he must have manifested his sharing of a common purpose with the perpetrators of the assault by himself performing some act of association with the conduct of the others. Fifthly, he must have had the requisite mens rea; so, in respect of the killing of the deceased, he must have intended them to be killed, or he must have foreseen the possibility of their being killed and performed his own act of association with recklessness as to whether or not death was to ensue."

It has been suggested (by the author in Kemp et al Criminal Law in South Africa 2ed (2015) $262 \mathrm{fn} 28$ ) that these requirements apply equally to all cases that involve common purpose, but that they are "more or less selfevident in cases where there is a prior conspiracy". However, as Snyman (Criminal Law 6ed (2014) 260-261) points out, there are important 
distinctions between the two forms of common purpose liability. Thus where reliance is placed on a prior agreement or conspiracy, as opposed to active association, proof of agreement with a general common design (rather than association with a specific act) will suffice for liability. Moreover, with regard to the prior agreement form, presence at the scene of the crime is not required, and it is further not required that the accused actively associated himself with the actual commission of the crime at the time of its commission (Snyman Criminal Law 260-261; S v Mzwempi supra par 54). In the fourth edition of Burchell (Principles of Criminal Law (2013) 467ff), the author introduces an entirely new understanding of the operation of the common purpose doctrine, in explaining the judgment in the case of Mzwempi (this argument is repeated in the latest 5 ed of this work (477ff)). Burchell's discussion is worthy of consideration. My interest is not merely personal Burchell disagrees with my own interpretation of the judgments in NzO and Mzwempi (see Hoctor "The State of Common Purpose Liability in South Africa" 2012 Journal of Commonwealth Criminal Law 180ff) - but because adopting this understanding would change the way we view the common purpose doctrine.

\section{$2 \quad S \vee M z w e m p i$ (and $S \vee N z o$ )}

Let us remind ourselves what was held in Mzwempi. The court was confronted with a case of faction fighting, and held that, although the appellant was a member of the armed force from the Manduzini clan which attacked the members of the Makhwaleni clan, the evidence before it was insufficient to establish beyond reasonable doubt: (i) that the appellant could be linked to any of the crimes flowing from the attack - murder, attempted murder and arson - in his individual capacity; or (ii) that the crimes had not already been committed before the point at which the appellant was positively identified as being present; or (iii) that the appellant was a party to a prior agreement to commit any of these crimes (par 36). The court's decision on the facts is not in dispute. However, the court's discussion of the legal position is somewhat more controversial, at least in one respect.

In discussing the law relating to the common purpose doctrine, Alkema $\mathrm{J}$, sets out the leading cases of $S v$ Safatsa (1988 (1) SA 868 (A) par 57-63), $S$ $\checkmark$ Mgedezi (supra par 64-72) and $S v$ Thebus (supra par 49 and 73-74), in which active association common purpose, which was in issue in each of these cases, was refined and authoritatively approved. However, the case of $S \vee N z o$ (1990 (3) SA 1 (A) par 80-93), which was not mentioned in the Thebus case, is singled out as unjustifiably extending the ambit of the common purpose doctrine, and on this basis, it is contended, it ought to be disregarded in favour of the Safatsa/Mgedezi line, approved in $S v$ Thebus (supra par 117). It was held by the trial court in Nzo that members of an undercover African National Congress group, who were engaged in acts of sabotage in Port Elizabeth, could be held liable for the murder of the victim, who had been killed by another member of the group after she threatened to inform the police about the activities of the group. Whilst there was no evidence that the accused were aware of the murder, or that they knew that it was going to be committed, nevertheless both their foresight of the 
possibility that the murder could occur, and their continued association with the common purpose of the group, had been established, and these factors were held to be determinative ( $S \vee N z o$ supra 4E-5F). On appeal, it was argued on behalf of the appellants that liability could not be imputed to every ANC member for every foreseen crime committed by another ANC member in the context of "a criminal campaign involving the commission of a series of crimes", and that liability should only extend to "crimes with which the accused specifically associates himself" (7E-F).

The majority of the court rejected this argument, however, stating that it was not concerned with the "liability of the members of the ANC for crimes committed by other members", and nor was it concerned with the "appellants' liability merely as members of the organisation" (7G-H). Instead, the majority held $(7 \mathrm{H}-\mathrm{J})$, the focus of the court was on the actions of three individuals who formed the "active core" of the ANC cell in Port Elizabeth, and who functioned as "a cohesive unit in which each performed his own allotted task":

"Their design was to wage a localized campaign of terror and destruction; and it was in the furtherance of this design and for the preservation of the unit and the protection of each of its members that the murder was committed."

The reasoning of the trial court was therefore approved by the Appellate Division (although the first appellant was acquitted on the basis of dissociation). This decision has been criticized by Burchell ("S v Nzo 1990 (3) SA 1 (A): Common purpose Liability" 1990 SACJ 345, which criticism is supported by the author in Kemp et al Criminal Law in SA 269 fn 62) for its apparent extension of the ambit of common purpose beyond acceptable limits, and the court in Mzwempi takes the same approach, holding that Nzo does not accord with the Safatsa/Mgedezi line approved in Thebus, and that it therefore need not still bind new cases in precedent. Alkema J, stated (par 111) that the consequence of applying the approach in Nzo would result in every ANC member at the time of being guilty of murder, or indeed, every member of the Manduzini clan being guilty of all the crimes: "a consequence not worthy of serious thought". (Snyman agrees that the majority decision in Nzo was flawed (a view first expressed in the 6ed of this work in 2014), and concurs with the criticism levelled against it in Mzwempi (Snyman Criminal Law 260 fn 40)).

Whilst the court's conclusion makes for compelling rhetoric, it is my submission that it is rather less compelling in law, as it is clear that the basis for founding the murder conviction on common purpose in Nzo, was not related to active association common purpose (as in Safatsa, Mgedezi and Thebus), but rather to common purpose founded on prior agreement: the "terrorist campaign" participated in, in the execution of a "common design" ( $S$ $v$ Nzo supra 7C). According to the majority judgment of the court, both such "common design" to commit acts of sabotage, as well as the foresight of the possibility that informers who posed a threat would have to be executed, had been established beyond reasonable doubt. 


\title{
$3 \quad$ Burchell's views examined
}

In an argument which is first introduced into the fourth edition of Principles of Criminal Law, Burchell defends the correctness of the judgment in Mzwempi, in the following terms. First, he states that the two forms of common purpose (which he refers to as "the two extremes") may overlap in practice:

\begin{abstract}
"For instance, there may be a prior agreement to commit crime $A$, and crime $B$ is also committed by members of the group. Provided crime $B$ was foreseen as a possible consequence of committing crime $A$ then the South African courts have indicated that liability of members of the group for committing crime B may result in terms of the common purpose rule, provided that crime $B$ is a so-called consequence crime. So, for instance, an accused who agreed, as a member of a criminal syndicate, to commit (or participate in the commission of) housebreaking with intent to commit a crime or robbery would be liable for murder if the resultant death was foreseen as a possibility of engaging in the agreed crime." (477-478 (5ed))
\end{abstract}

The idea of "overlap" between forms of common purpose may be somewhat misleading. After all, a crucial aspect of liability on the basis of the common purpose doctrine is that the relevant intent must extend to that particular crime. Even if a number of crimes flow from the same course of criminal conduct, it is essential that the common purpose relates to each individual crime in order for liability to follow. "Intent" is evaluated separately for each crime, and is not based on other criminal conduct.

Burchell continues (478) that "there must [be] a specific agreement to commit crime $A$ and, it is submitted, some similarity in nature between crime $A$ and crime B" (original emphasis). As it stands, this statement is entirely novel, and does not seem to be backed up by any authority. Once again it bears iteration that the key consideration in this regard would simply be whether the accused had the necessary intention to commit the relevant crime, along with the necessary act of association with the conduct of the others. To add this particular requirement, as Burchell does, would appear to be without justification, and would only serve to limit the operation of the common purpose doctrine, an outcome which was not sought by the Constitutional Court in Thebus.

The key concern of Burchell, as also of Alkema J, in Mzwempi, was to exclude the perceived impact of Nzo. Thus Burchell (479) praises the approach adopted in Mzwempi as "surely correct" in holding that

"foresight of the possibility of the commission of crime B cannot, simply in conjunction with membership of a group that may, in itself, be unlawful or where the group sanctions or engages in some nefarious activities, be sufficient to hold a member liable for all of the foreseen crimes ultimately committed by other members of the group."

In this regard it may simply be pointed out that the majority of the court in $N z o$ was at pains to point out that the effect of the common purpose doctrine extended only to the appellants in this case, and did not seek to draw a broader interpretation extending to the liability of other ANC members engaged in the armed struggle (7G-I). As mentioned earlier, this extended application was the substance of the contentions on behalf of the appellants, 
and this proposition was indeed accepted by MT Steyn JA, in his minority judgment in Nzo (17B-D). However, as Alkema J, points out in Mzwempi (par 96), the "extended liability" approach, which it is argued Nzo champions, has simply not been applied in any subsequent case, and most notably, not in Thebus (par 11). The reason for this is self-evident, it is submitted. Just as the majority stated, the dictum in the case was never meant to be of general application, but rather to apply to the particular factual scenario in the case of $N z o$, which involved a prior agreement. Similarly, the reason why the court in Nzo did not refer to either the Safatsa case or the Mgedezi case (which is queried in the Mzwempi judgment, par 90), is because these latter cases involved active association common purpose; thus a different form of common purpose to the Nzo case.

In fact, it is submitted that there is no "extended liability" advocated in $\mathrm{Nzo}$, given that this case deals with a prior agreement rather than active association, which is characterized by a considerably less restrictive application, as acknowledged in Mzwempi on a number of occasions (par 20,53 and 77 ). It is evident from this categorization that the application of the common purpose doctrine in Nzo is akin to a robbery involving three participants, where one robber, prior to the robbery, threatens to kill anyone who offers resistance to the taking, whilst the other two robbers participate, hoping that this will not occur, despite their foresight of this possibility. Should a killing ensue, the latter two robbers would be held criminally liable for murder, unless they dissociate themselves from the crime (the example in Mzwempi (par 55) has application). Similarly, in S v Musingadi (2005 (1) SACR 395 (SCA)), a murder conviction was confirmed for two accused who left the scene of the robbery, in which they were involved by prior agreement, when it was clear that the other accused were determined to kill the victim, whom they had helped to subdue and restrain. The court held that, in the absence of any meaningful dissociation from the ensuing killing in these circumstances, the two accused were guilty of murder (par 34 and 40). It is further clear that it was held to be established by the Appellate Division in Nzo that the accused foresaw the possibility of the death of the victim, having informed the person who carried out the killing, Joe, of her threats to go to the police, and that they were reconciled to this possibility for the sake of silencing the potential informer in order to protect the group (5J-6F). Given that it has been accepted that the exact manner in which the consequence occurred does not have to be foreseen (see the more recent statement in this regard in S v Molimi (2006 (2) SACR 8 (SCA) par 33). It seems clear that the result in Nzo was not an unwarranted deviation from the doctrine of common purpose, which wrongly extended the ambit of its application, but rather an application of the doctrine in the context of a prior conspiracy (which can come about even tacitly - Snyman Criminal Law 288), where though direct intention to kill could not be established, dolus eventualis was proved beyond reasonable doubt (5F-6F). Crucially, the accused did not deny their foresight of the possibility of the killing, nor their subsequent continuation in the course of conduct, with no indication of dissociation and no evidence to refute such intent. Whilst defence counsel raised a worthy spectre of untrammelled liability $(7 C-G)$, as did MT Steyn $\mathrm{JA}$, in his minority judgment (17B-E), liability was founded on the facts of the 
case, and the state of mind of the individual accused, in applying this particular, far less restrictive form of common purpose liability, based on prior agreement.

Does this mean that the common purpose doctrine could never apply in an analogous future situation involving membership of an organization or group which has the specific aim of carrying out violent or destructive acts? It is submitted that it certainly could - this is after all the nature of the common purpose doctrine, particularly in the form of a prior agreement - but all the elements of the common purpose would have to be established beyond reasonable doubt for this conclusion to be reached.

Burchell contends (478 fn 27) that I am mistaken in categorizing the Nzo case as one of prior agreement, whereas "the argument for liability in both Nzo and Mzwempi was based on reliance on neither a pure prior agreement nor a pure active association model, but rather ... [a] hybrid situation". It is submitted that, to accept that, apart from the well-established dichotomy of prior agreement and active association common purpose, a further hybrid category of common purpose exists, runs contrary to all existing authority, which very clearly affirms that there are only two forms of common purpose (see the leading cases of $S v$ Mgedezi supra 705E-706C; $S v$ Thebus supra par 19; and Burchell's own definition which has found acceptance in the courts, cited above). If there were to be a hybrid variant of these two forms, this would inevitably give rise to considerable legal uncertainty. What requirements would pertain to such a form of liability? Would such a form of liability be restrictively interpreted, as with active association common purpose, or unrestrictively interpreted, as with prior agreement common purpose? Would the answer to the previous question be based on which of the existing forms the hybrid form is closer to, on the facts of the case? On what basis would a court assess this? It is submitted that the introduction of such a vague concept into a well-settled area of the law could only spell difficulty for the courts, and potential peril for accused, who would not be able to predict how the common purpose doctrine would be applied.

Moreover, the so-called hybrid approach is not postulated or contended for in either Nzo or Mzwempi. In Nzo the court is plainly dealing with the question whether there was sufficient evidence of the appellants' "continuing participation in the execution of the common purpose, despite their foresight of the possibility of the murder" (7B-C). This was accepted as proved beyond reasonable doubt by the majority of the court, which held that the appellants intended the specific crime of murder, whereas the minority (MT Steyn JA) held that all that could be established was a general common intent to commit terror activities, rather than a specific intent to kill, and that the common purpose doctrine could not find application (17B-E). There is no indication of any hybrid approach or application outside of the two standard forms of common purpose. Similarly, in Mzwempi, Alkema J rejects the argument of counsel for the State that the "attack and its strategy were preplanned and agreed" (par 19 and 36), before determining that the appellant, while part of the attacking force (par 36), could also not be established to have associated himself with the commission of any of the crimes with which he was charged (par 36). Once again, no hybrid approach 
was relied on, and the court consequently does not comment on any novel or unusual application of the common purpose doctrine apart from the two well-accepted forms of the doctrine. Therefore, in both cases, if the court had any thoughts regarding the application of a "hybrid" approach, this is in no way evident from the judgment.

In fact, having stated that the basis for a guilty verdict for murder in Nzo was neither pure prior agreement nor pure active association, Burchell himself classifies Nzo differently later in his discussion; thus rather contradicting his earlier characterization of the Nzo case as an example of a hybrid approach. Burchell states that "there was no prior agreement between the appellants to kill the deceased", and proceeds to analyse the case in terms of the active association common purpose requirements, as set out in $S \vee$ Mgedezi (supra 500-501), criticizing the judgment in Nzo for nonfulfilment of these requirements. Further, Burchell criticizes my assessment of Mzwempi (479 fn 30) for "classifying the case in hand as 'active association' rather than 'prior agreement' [common purpose]". I do no such thing, and have commented elsewhere that the application of law to the facts in Mzwempi "cannot be faulted" ("General Principles and Specific Offences" 2011 SACJ 201 207, and see above). My concern is with the misinterpretation of the Nzo case. Nevertheless, Burchell proceeds to state (479 fn 30) that "Mzwempi is both a prior agreement (to commit crime A ie, assault, arson and public violence) and alleged active association in crime $B$ (murder)" (original emphasis), and that Alkema J, was therefore "quite correct in applying the restrictive active association principles set out in ... Mgedezi ... and approved in ... Thebus ..." However, as indicated above, Alkema $\mathrm{J}$, carefully sought to apply both the rules of prior agreement common purpose, and then the rules of active association common purpose, to the facts, and found that the requirements for neither form of common purpose had been satisfied, and therefore that liability could not follow for the appellant. So, in fact, contrary to Burchell's statement, Mzwempi is not an example of either the prior agreement or the active association forms of common purpose. It is, on the facts and as the court correctly held, an example of neither.

The Appellate Division has in any event categorized Nzo as an example of the prior agreement form of common purpose in $S v$ Singo (1993 (1) SACR 226 (A) $232 \mathrm{~F}-\mathrm{G}$ ), describing the judgment as one dealing with "express agreement or conspiracy". This flies in the face of defining the approach adopted in Nzo as "hybrid". For all these reasons, it is contended that Burchell's defence of the approach adopted to the Nzo case in Mzwempi is not correct.

\section{$4 \quad$ Concluding remarks}

In conclusion, it is Burchell's contention that the Mzwempi case has made an important contribution to the law relating to common purpose in ridding the law of the pernicious effects of $\mathrm{NzO}$ (479):

"The only way to make sense of the practical extension of common purpose liability to this hybrid of prior agreement and active association is to recognise 
that specific agreement to commit crime $A$ and active association in crime $B$ is required for criminal liability for crime $B$ and so the courts would have to apply the most restrictive common purpose rule, viz the Mgedezi active association

limits to this hybrid situation. This is what Alekema [sic] J did in Mzwempi."

It is my contention that there is no need to resort to such convoluted reasoning. In fact, the Mzwempi case greatly overstates the effect and influence of $N z o$, and mistakes the form of common purpose liability which applies. No doubt the Nzo judgment will always leave some with a sense of disquiet, but if one simply focuses on the operation of the legal principles involved, it is submitted that one cannot find fault with it. It was held that liability for murder could follow where saboteurs (in this case) were engaged, by virtue of a pre-existing plan, in waging operations to overthrow the Government, and such saboteurs foresaw the possibility of such activities necessitating the killing of anyone who stood in the way of their achieving their objectives. This finding involves a simple application of the doctrines of common purpose and dolus eventualis. If the political allegiances were reversed, and a democratically-elected government faced a threat from radical right-wing saboteurs, on the same facts the same result should be obtained. Nothing in the Thebus judgment would suggest otherwise.

Shannon Hoctor University of KwaZulu-Natal, Pietermaritzburg 